\title{
Investigating the Integration of Cloud Computing in Medical Information Systems Using a Two-Stage Model
}

\author{
Chen-Lin Lee ${ }^{*}$, Li-Chuan $\mathrm{Chu}^{2}$, Kuo-Chung Huang² \\ ${ }^{1}$ Department of Business Administration in Nanhua University; Buddhist Dalin Tzu-Chi Hospital, Chia-yi, \\ Taiwan. \\ 2 Department of Business Administration in Nanhua University, Chia-yi, Taiwan. \\ * Corresponding author. Email: allen@tzuchi.org.tw \\ Manuscript submitted April 30, 2015; accepted Mary 18, 2015. \\ doi: $10.17706 /$ jcp.10.5.354-364
}

\begin{abstract}
Although the development of cloud computing has gradually matured, studies on the use of cloud computing for medical information systems remain deficient. In this study, a two-stage model was used to perform related analysis. Stage One of the model employed a mathematical model to estimate the cost model for self-built information systems as well as the involved risk loss. The difference in the information systems' costs and operational performance with and without cloud computing technology were discussed. Stage Two of the model used the technology acceptance model integrated with the flow theory to investigate the behaviour and attitude of the medical staff toward cloud computing technology, the criteria for them to accept the technology, and their subsequent continuous use intention. The moderated structural equation modelling results generally supported the hypotheses. The article concludes by discussing the theoretical and implications of the research findings. This research offers management the opportunity to asset the overall hospital information system process and improve efficiency and effectiveness.
\end{abstract}

Key words: Cloud computing, technology acceptance model, flow.

\section{Introduction}

Within the information technology industry worldwide, cloud technology has been regarded as the sector providing the largest business development opportunities. Cloud computing can be used to process and compute large-scale data, in addition to offering a variety of platforms that enable information system integration and application software development. Cloud computing both provides hardware facilities that significantly reduce the costs of information equipment purchases for lessees and decrease the number of information maintenance personnel required. Because cloud computing technology features superior information processing efficiency and performance, medical institutions have focused on the feasibility of using cloud systems to store medical information. The information systems used by most hospitals are self-built. Additionally, software development, hardware purchases, system updates, and the costs of subsequent regular maintenance and parts repair are expenditures borne by the hospitals to facilitate system operation. Because medical information systems (MISs) are closely related to the hospitals' overall operation, they demand hospitals' utmost attention. Currently, hospitals face two potential information system-related problems; first, the large data volume accumulated over time has resulted in data storage and retrieval delays, not to mention that the volume of the data to be processed continues to increase daily, which would profoundly influence the information system operations within a hospital. Second, because 
the developed MIS interfaces offer poor integratability and expandability, they limit the hospitals' ability to develop their information systems. Consequently, these problems demand valid solutions, and the introduction of the cloud system may be the optimal solution among those currently available.

Shi, Zhang, and Li [1] indicated that cloud computing tenants face new challenges in secure data storage, including challenges related to data privacy and securing data stored on untrustworthy servers. Whether computing technology can be accepted by medical institutions depends on the ability of cloud system supplier to propose appropriate measures for ensuring uninterrupted service and secure access to network data and for protecting the system from malicious program attacks. Most importantly, a transparent security management system must be in place. Cloud technology is a crucial information technology of this century; it has been gradually accepted by businesses in various industries, features several advantages, and creates corporate competitive advantages. However, studies that employ information system costs and risk aversion capability to assess the feasibility of using cloud computing systems in hospitals remain scant. Therefore, this study adopted a two-stage model to perform analysis. Stage One of the model involves employing a mathematical model to estimate the cost model of a self-built information system as well as the relevant risk loss, and subsequently analyse the difference in the information systems' costs and operational performance with and without cloud computing technology. Stage Two of the model used the technology acceptance model (TAM) combined with the flow theory to investigate the behavior and attitude of medical staff toward cloud computing technology, the criteria for them to accept the technology, and their subsequent continuous use intention (CI). The next section presents the proposed research hypothesis, the underlying construct and moderating variables, as well as the measurement items. Various construct variables and items were validated using factor analysis. The final section of the study presents the conclusion and a discussion regarding cloud computing and its key features.

\section{Estimating the Costs to Build the Information System}

The most unique characteristic of cloud computing is its ability to effectively allocate resources and to manage information data in a distributed and extensive manner, supporting a number of platforms, systems, and applications [2]. The reason most large-scale businesses use cloud platforms is to reduce the cost required for developing information systems and hiring system maintenance personnel. Specifically, it minimizes the probability and risks of information system damage. In other words, once businesses build their own information systems, they must make monetary investment in various software and hardware equipment and in hiring additional personnel to maintain the operation of the information system. Previous studies have rarely investigated the costs of building information systems for hospitals. Therefore, this study used a mathematical model to estimate a cost model for information systems. In general, building information systems involves considering the costs of purchasing software and hardware equipment. Software costs can be estimated by using the expert consulting, estimation by analogy, and parametric modelling (also known as the algorithm modelling) methods. The basic concepts behind software cost estimation are to view software scale and the adjustment factor as functions, where the number of operating function points may be used to represent the software scale function. This study assigned the software scale function as $\alpha \mathrm{n}$ and the hardware scale function as bn. The adjustment factor function, gi(y), denotes all other factors, in addition to the software scale factor, that led to an increase in software system development costs. Because the factors exhibited varying levels of effect, they were summed to reveal the total effect. This paper used an algorithm modelling for software cost estimation [3] as given by

$$
C_{1}=\left(a_{n}+b_{n}+k\right)+\sum_{i=1}^{n} g_{i}(y)
$$

where 
$C_{1}$ is the cost estimation for building the information system.

$\alpha_{n}$ is the software cost estimation.

$b_{n}$ is the hardware cost estimation.

$i$ is the installation of the information system, $i=$ the number of adjustment factors (e.g., 1, 2, 3, .., $n$ ).

$y$ is the vector of the adjustment factor.

$k$ is a constant.

When developing information systems, developers have to consider both initial investment costs and the costs of regular maintenance. When equipment fails, they need to repair parts immediately. The equipment maintenance cost accumulated within time $t$ is defined as follows:

$$
C_{2}=\int_{0}^{t} \sum_{j=1}^{m} \beta * p_{j} d t
$$

where

$C_{2}$ is the regular maintenance cost estimation

$B$ is the unit node enabling the cost estimation (including maintenance and labor costs)

$P_{j}$ is the cost to repair each system's parts; $j=1,2,3 \ldots, m$.

\subsection{Information System Risk Loss Estimation}

In addition to the aforementioned costs, information systems also face risks in their development, usage, and maintenance stages. Unfortunately, risks are a potential factor that is unpredictable. Potential risks include system failure, database corruption, and the loss of crucial and confidential data, leading to losses caused by offline operations or system downtime. In this study, risks were assumed to primarily comprise two variables: risk probability and risk loss. Risk probability refers to the probability that risks will occur, and risk loss refers to the extent of losses once those risks occur. IT system risks were expressed using the following equation (Eq. 3):

$$
C_{3}=\int_{0}^{t} \sum_{j=1}^{m}\left(R_{j} * L_{j}\right) e^{\delta t} d t
$$

where

$C_{3}$ is the loss resulting from associated risks.

$R_{j}$ is the probability that the $j$ th risk will occur.

$L_{j}$ is the extent of losses caused by the $j$ th risk.

$e^{\delta t}$ is the present loss transform rate.

By adding (1), (2), and (3), (4) was obtained, where Ct is the estimated total investment cost. Subsequently, substituting functions (1), (2) and (3), yielded (4).

$$
C_{t}=\left(a_{n}+b_{n}+k\right)+\sum_{i=1}^{n} g_{i}(y)+\int_{0}^{t} \sum_{j=1}^{m} \beta * P_{J} d t+\int_{0}^{t} \sum_{j=1}^{m}\left(R_{j} * L_{j}\right) e^{\delta t} d t
$$

$R_{j}$ was used to estimate risks potentially occurring in the $j$ th information system. Eq. (3) expresses the estimated risk loss from project period time 0 to time t prior to the implementation of the cloud system; (5) is the cost of introducing cloud technology to the information system, which includes not only the fixed costs comprising the rental of the cloud platform and bandwidth, but also the estimated cost of potential risk loss. To reduce the expected loss, the $e-\delta t$ index was added in (5) to represent the risk transfer that may occur after introducing cloud technology to the information system. 


$$
C_{4}=\int_{0}^{t} \theta+\sum_{j=1}^{m} \alpha\left(R_{j} * L_{j}\right) e^{\delta t} d t
$$

where

$C_{4}$ is the total investment cost involved in using cloud computing

$\theta$ is the fixed cost (cost of cloud platform rent and bandwidth)

$\alpha$ is the risk coefficient $0 \leq \alpha \leq 1$

The risk management performance of the developed system could be measured by comparing the risk loss prior to building the system and after project implementation to calculate the risk reduction cost-benefit ratio, where a low risk reduction cost-benefit ratio indicates a satisfactory risk control. The related equations (6) and (7) are shown as follows:

Risk Reduction Cost-Benefit Ratio $($ RRCBR $)=$ (Losses from risks before implementing cloud computing losses from risks after implementing cloud computing)/cost of establishing the information system(6):

$$
\frac{\left.\int_{0 j=1}^{t} \sum_{j=1}^{m}\left(R_{j} * L_{j}\right)\right)^{\delta t} d t-\int_{0}^{t} \theta+\sum_{j=1}^{m} \alpha\left(R_{j} * L_{i}\right) e^{\delta t} d t}{\left(a_{n}+b_{n}+k\right)+\sum_{i=1}^{n} g_{i}(y)+\int_{0}^{t} \sum_{j=1}^{m} \beta * \mathrm{P}_{j} d t}
$$

This study primarily emphasized the concept of using information systems. However, the calculation of risks entails considering the probability for each risk to occur, and the losses incurred from these risks can only be determined after the collection of sufficient historical data. Therefore, in this study, these equations were merely used for inferring, and numerical values were not employed as examples. The above discussion demonstrated the cost of developing an information system and the estimated risk loss. If that the cost of building an information system (e.g., the cost of purchasing software and hardware equipment, performing regular maintenance, and bearing the risk loss) outweighs the fixed costs and risk loss involved in introducing cloud computing into a MIS, this condition will satisfy the requirement for a hospital to incorporate cloud platform into its MIS, as shown in (8). Conversely, if the costs of using the MIS in a cloud platform are higher than those estimated for developing a self-built MIS, the cloud platform will not be considered.

$$
\begin{aligned}
\left(a_{n}+b_{n}+k\right)+ & \sum_{i=1}^{n} g_{i}(y)+\int_{0}^{t} \sum_{j=1}^{m} \beta * P_{j}+\int_{0}^{t} \sum_{j=1}^{m}\left(R_{j} * L_{j}\right) e^{\delta t} d t \\
& \geq \int_{0}^{t} \theta+\alpha \sum_{j=1}^{m}\left(R_{j} * L_{j}\right) e^{\delta t} d t
\end{aligned}
$$

\subsection{Study Objective}

Cloud computing has emerged as the next generation of information production, and is used by increasing number of businesses. However, despite this, studies in the field of medical information have rarely investigated the willingness among hospital personnel to use or accept cloud-based information systems. To determine users' level of acceptance for cloud information systems and to ensure that they use the cloud computers efficiently, this study applied the theory-based TAM [4] to investigate the behavior and attitude of hospital users toward cloud computing, the criteria for them to accept the technology, and their subsequent $\mathrm{CI}$ to build an optimal study model. The TAM was derived to apply to any specific domain of human-computer interactions. TAM asserts that two salient factors - perceived usefulness (PU) and 
perceived ease of use (PEOU) - determine technology acceptance and the attitude toward technology (ATT) and CI of a cloud-based computer system. Though empirical research has focused on the TAM model to determine the willingness among users to use cloud-based systems, less is known about the factors that render cloud computing a compelling experience for users. Hoffman and Novak [5] proposed that commercial web sites would benefit by facilitating what has been called the experience of flow, and argued that usage of an online environment should be directed to providing flow opportunities where the user is completely engaged in interaction [6] with the cloud platform. In particular, prior research has not examined flow experience in relation to the $\mathrm{CI}$ of cloud computing systems. Second, previous researchers who used TAM merely focused on the effects of users' attitude toward using technology systems on their intention to continue to use the system; however, they failed to consider users' personal experiences in the virtual environment. Therefore, Hoffman and Novak [6] proposed that customer experience is critical, and underlies the idea of facilitating flow experience in the Internet environment. However, their findings are not conclusive, because their samples and measurements of both TAM model and flow are diverse. To fill the gaps in the literature, in this study, the TAM was improved through the integration of flow theory, to observe additional research constructs and provide increased credibility and effectiveness.

\section{Research Model and Hypotheses}

In this study, PEOU is defined the degree to which a person believes that using a particular system (cloud computing) would be free of effort [4]. Concerning users' cognitive behavior, researchers have argued that when users perceive a cloud computing system design as complex, this perception reduced their intention to use the system [7] and subsequently influenced their attitude toward accepting the system. In addition, prior research has empirically verified that a significant relationship between PEOU and ATT does not exist [8]-[10]. This insignificant PEOU-ATT relationship may be attributed to the fact that PEOU had seldom been studied when the users perceive a higher level of usefulness and relative advantages to using cloud computing. Thus, this study tested the following hypotheses:

H1: Users possessing a high level of PEOU of the cloud system operation tend to exhibit a positive attitude toward using the system.

PU is defined the degree to which a person believes that using a particular system (cloud computing) would enhance his or her job performance [4]. Furthermore, research has indicated that the construct variable of PU plays a critical role in explaining user acceptance and behavior regarding IT systems [11]. Therefore, the following hypothesis was proposed:

H2: Users demonstrating a high level of PU regarding the operation of the cloud system tend to exhibit a positive attitude toward using the system.

Attitudes can be formed based on information about past behavior, affective information, and cognitive information [12]. Ajzen and Fishben [13] demonstrated that attitudes toward an object influence intentions and ultimately influence behavior and use of the object. Empirical studies have provided evidence indicating that ATT has a significantly positive effect on use intentions [8], [14]. Thus, this study tested the following hypotheses:

H3: Attitude towards using the cloud computer has a positive effect on the continuous use Intention.

\subsection{Moderator Role in the Relationship between ATT and CI}

Originally, flow was characterized by [15] as the integration of a clear goal, feedback, and concentration: a state in which self-consciousness disappears and the sense of time is distorted. Bakker [16] proposed that flow is a short-term peak experience at work. Hoffman and Novak [6] emphasized that flow occurs in human-computer interaction, specifically, in interaction with information technology systems. Prior research has found that employees who use their computers in unproductive ways (e.g., sending personal 
e-mails, playing computer games) tend to concentrate less than others [17]. In other words, when employees are goal-oriented and engaged in concentration (i.e., two of the components character of flow), their flow experience strongly influences their in-role performance, because of their immersion in work tasks [18]. Not surprisingly, flow is one of the most valid personality predictors of human-computer interaction internal factors, and plays a role in influencing attitudes and subsequent behavioral intentions. Flow has been found to influence attitude [9], [19] and CIs [10], [20]. The assumption in the present study is that flow will qualifies ATT-CI relationship, and acts as a moderator. Therefore, the following hypothesis was proposed:

H4: The relationship between AT and $\mathrm{CI}$ is moderated by flow. Compared with employees who infrequently experience flow, those who frequently experience flow demonstrate the relationship between ATT and CI.

\section{Research Methodologies}

The items chosen for the constructs were adapted from a previous study to ensure content validity. all constructs were measured using five-point Likert scales.

\subsection{Data Collection and Sample}

The research participants were medical personnel in Southern Taiwan who had at least one year of working experience. Before filling out the questionnaires, the respondents were informed of the academic purpose of the study, and that their responses would be kept confidential. This procedure ensured an effective response rate and data quality control. After excluding 46 invalid questionnaires, the total number of valid samples was 182, yielding a response rate of $65.2 \%$. Demographically, $64 \%$ of the respondents were women; 52\% were aged between 31 and 40; and 23\% were aged between 20 and 30. Most respondents had been educated to the university level. All items among the constructs were evaluated against demographic controls (gender, age, level of education), and a t test or ANOVA was used. The results revealed that the two and three groups were not significantly different $(p>.05)$, suggesting that the sample collection was valid.

\subsection{Measurement Model}

Data analysis was performed using a multistep approach. The models were assessed by the maximum likelihood method using AMOS17.0. A structural equation model was developed to test the hypotheses. To evaluate the model fitness, a chi-square test with degrees of freedom, the goodness of fit index (GFI), the adjusted goodness of fit index (AGFI), the normal fit index (NFI), and the root mean square error of approximation (RMSEA) were employed. A good fitness is normally deemed to exist when GFI and NFI are greater than 0.9, the AGFI is greater than 0.8, and RMSEA is less than 0.08. As Table 1 shows, the measurement model indicated that factor loadings of all items ranged between 0.545 and 0.890 . The composite reliability (CR) values ranged from 0.762 to 0.836 , and average variance extracted (AVE) values ranged from 0.520 to 0.630 . For all measurements, both indices were higher than the evaluation criteria, namely 0.6 for CR and 0.5 for AVE [21]. Flow was measured as a single construct, and the measurement model was estimated using AMOS. The results suggested a good fit of the second-order $\chi^{2}=55.287, \mathrm{df}=31$, $\mathrm{GFI}=0.964, \mathrm{AGFI}=0.928, \mathrm{NFI}=0.945, \mathrm{RMSEA}=0.053)$, and indicated an acceptable fitness. As Table 1 shows, all item standardized loadings and estimates were positive and significant, evidencing convergent validity [21]. Lastly, the chi-square difference test was performed for all constructs in pairs to examine whether the restricted model significantly differed from the freely estimated model. In the restricted model, the correlation was fixed at one for the pair of constructs under examination. The results supported discriminant validity [22]. 


\subsection{Testing the Structural Equation Model}

In this study, the structural equation model was tested using the maximum likelihood method. As Table 3 shows, a comparison of all fit indices with their corresponding recommended values indicated a good model fitness $\left(\chi^{2}=21.413, \mathrm{df}=17, \mathrm{GFI}=0.963, \mathrm{AGFI}=0.924, \mathrm{NFI}=0.953, \mathrm{RMSEA}=0.049\right)$. To examine the hypotheses using the structural equation model, the results, shown in Table 2, demonstrated that PEOU had direct effects on ATT $(t=7.28 ; p<.001)$, and indicated support for H1. ATT had direct effects on CI $(t=$ $5.46 ; p<.001)$, providing support for H3. Unexpectedly, PU had weak significant effects on ATT $(t=2.805 ; p$ $<.01$ ); this contrasted with findings in prior studies [23].

\subsection{Testing the Moderating Effect of Flow}

Multigroup causal analysis was used to test the moderating effect of flow in this study. Respondents were split into high and low groups based on their perceptions of flow. The analysis included a two-group comparison to examine whether there were differences in structural parameters between high and low values of the variable. A significant difference between the two tests (chi-square difference) indicated that the variable used for splitting the samples moderated the relationship studied. As shown in Table 3, the chi-square difference was 8.9 ( $p<.001$ ) for the ATT-CI link, exceeding the critical value of 3.8 for one degree of freedom. The results indicated that the positive effect of ATT on CI was higher for the group of employees that frequently experienced flow. These results are consistent because employees that frequently experience flow have positive attitudes toward work, and may have confidence and optimism, which would result in ambition and a focus on career goals. Thus, flow positively moderates the effect of ATT on CI, confirming H4.

Table 1: Confirmatory Factor Analysis and Scale Reliability

\begin{tabular}{|c|c|c|c|c|}
\hline Item & $\begin{array}{l}\text { Standardized } \\
\text { Loading }\end{array}$ & t-value & SCR & AVE \\
\hline PU & & & & 0.549 \\
\hline PU1 & 0.774 & 12.134 & 0.784 & \\
\hline PU2 & 0.784 & 12.355 & & \\
\hline PU3 & 0.658 & 10.213 & & \\
\hline PEOU & & & & 0.630 \\
\hline PE1 & 0.751 & 13.576 & & \\
\hline PE2 & 0.861 & 14.601 & 0.836 & \\
\hline PE3 & 0.764 & 12.136 & & \\
\hline $\mathrm{CI}$ & & & & 0.533 \\
\hline CI1 & 0.668 & 9.317 & & \\
\hline $\mathrm{CI} 2$ & 0.602 & 8.258 & & \\
\hline CI3 & 0.889 & 14.850 & 0.769 & \\
\hline ATT & & & & 0.520 \\
\hline AT1 & 0.810 & 14.083 & & \\
\hline AT2 & 0.606 & 9.116 & & \\
\hline AT3 & 0.732 & 13.251 & & \\
\hline Flow total & & & 0.762 & 0.608 \\
\hline FL1 & 0.890 & 16.344 & & \\
\hline FL2 & 0.858 & 16.061 & & \\
\hline FL3 & 0.545 & 9.683 & & \\
\hline FL4 & 0.855 & 16.154 & & \\
\hline FL5 & 0.713 & 15.435 & 0.817 & \\
\hline FL6 & 0.850 & 16.811 & & \\
\hline FL7 & 0.625 & 10.214 & & \\
\hline FL8 & 0.774 & 15.788 & & \\
\hline
\end{tabular}

\section{Discussions}


The purpose of this research was to develop a technology acceptance model integrated with flow theory to explore the factors that affect employees' attitudes toward using cloud computing, and how these attitudes, in turn, affect CIs.

Table 2. SEM Path Coefficients

\begin{tabular}{lllll}
\hline Hypothesis & $\begin{array}{l}\text { Path } \\
\text { coefficients }\end{array}$ & t-value & Significant & Supporting \\
\hline H1 PEOU $\rightarrow$ ATT & 0.561 & $7.283^{* * *}$ & Y & established \\
H2 PU $\rightarrow$ ATT & 0.233 & $2.805^{*}$ & Y & established \\
H3 ATT $\rightarrow$ CI & 0.412 & $5.460^{* *}$ & Y & established \\
fit indices: & & & \\
$\chi^{2}=21.413, \mathrm{df}=17, \mathrm{NFI}=0.953$, & GFI=0.963, & AGFI=0.924 & \\
\multicolumn{4}{c}{ RMSEA $=.049$} & , \\
\hline \multicolumn{4}{c}{ Note: $t$-value is significant at $p<.05$ when the t-value exceeds 1.96.}
\end{tabular}

Table 3. Chi-square Difference Test between Low and High Flow Experience Groups Constrained Model Unconstrained Model $\Delta \chi^{2}$

\begin{tabular}{|c|c|c|c|}
\hline \multicolumn{4}{|l|}{ Fit index: } \\
\hline Chi-square (d.f.) & $121.1(26)$ & $112.2(25)$ & $8.9^{* * *}$ \\
\hline GFI & 0.911 & 0.925 & \\
\hline AGFI & 0.892 & 0.893 & \\
\hline NFI & 0.924 & 0.924 & \\
\hline \multirow[t]{3}{*}{ RMSEA } & 0.042 & 0.043 & \\
\hline & & \multicolumn{2}{|c|}{ frequency flow experience } \\
\hline & & High & Low \\
\hline H4: & & & $0.55^{* * *}$ \\
\hline $0.21^{*}$ & & & \\
\hline
\end{tabular}

The purpose of this research was to develop a technology acceptance model integrated with flow theory to explore the factors that affect employees' attitudes toward using cloud computing, and how these attitudes, in turn, affect CIs. The significant finding of this study is that PEOU exerts a positive and significant effect on ATT. The results were consistent with previous studies [23]. However, at the current stage, the introduction of cloud computing to MISs still faces a number of obstacles. Users must first accept the advantages offered by the cloud system such as the provision of enormous data access space, the ability to develop and run programs on a virtual platform, high computation speed and system stability, and the ability to effectively reduce risks. This indicates that MISs will most likely use cloud computing in the future. Once users agree that cloud systems are a novel technology with prospective development potential, they will cognitively develop higher expectations for the system, which will subsequently be reflected in their attitude toward accepting the technology.

One of the most interesting findings, which contrasts with findings in prior studies [24], [25], was the weak effect of PU in predicting ATT. One possible explanation may be that when workstations and personal computers are linked to the cloud system, only the user interface is converted to such an extent that does not substantially influence users. This study thus hypothesized that users are actually concerned about the level of complexity of the involved operating procedures and the execution speed of the system. In other words, when the cloud operating procedures are overly complex, users cannot adapt to the system immediately, prompting them to reject the system, which is then reflected on their willingness to accept the new system. In practice, system users are generally not overly concerned with whether the system is built using a cloud platform or on the hospital's internal server; they are more focused on whether the information system enables them to complete their current workload quickly. 
This study found that ATT exerts a positive and significant effect on CI. This was consistent with previous studies [8], [14]. Karahanna, Straub, and Chervany [26] proposed that gaining experience with a system to reinforce the link between a user's attitude and behavioral intention. Because of subjective perception, users acquiring positive experiences from using the cloud system are more willing to use the system.

The results demonstrated that flow, specifically a high flow, exerted a significantly positive moderating effect on the relationship between ATT and CI. This result supported H4 of this study. The present study is one of the first to provide evidence for the moderating role of flow in the relationship between ATT and CI, although it would seem logical to expect that when employees have a positive attitude and frequently experience flow have greater continued use intentions when using cloud platforms. From a generalized perspective, this argument supported the broaden-and-build theory proposed by [27], who asserted that positive emotions induced positive thoughts and actions. By integrating flow into the system usage experience, employees can be immersed in activities crucial for achieving the performance standards [18]. Most likely, these people, because of their positive experiences, build up comprehensive processes which make them more willing and more able to harbor CIs for systems. According to the findings of this study, flow plays a moderating, rather than causal, role in the prediction of CI.

\section{Conclusions}

A few research contributions can be summarized from the results of this study. First the cloud system concept was introduced to MISs, to overcome the difficulties that traditional MISs have when saving and retrieving data. This improved system flexibility and expandability, creating a basis for relevant studies in the future. Second, this study established a model to estimate the cost of developing an information system. Regarding the information system cost estimation, the notions of cost allocation and cost reduction were emphasized, and used the basic concept from the algorithmic models to construct the function between the cost and efficiency. The equations were used to define the risk reduction leverage value as the basis of this study to support the arguments of this study that using cloud computing can avert risks and reduce the costs of developing, maintaining, and upgrading an information system as well as labor costs. A third contribution was its improvement to the TAM model; flow theory was integrated to allow additional research constructs to be observed, increasing the credibility and effectiveness of the study. This research validated the integration of the TAM and flow theory in the cloud context, and provided further understanding into employees' perceptions regarding the use of cloud computing. Cloud computing is the next generation of information production, but is also fast and economical, and is highly competitive with existing information systems. The study offers managers an opportunity to assess the overall hospital information system management process, and increase efficiency and effectiveness.

\section{References}

[1] Shi, Y. L., Zhang, K., \& Li, Q. Z. (2011). Meta-data driven data chunk based secure data storage for SaaS. International Journal of Digital Content Technology and its Applications, 5(1), 173-185.

[2] Poonam, B., Sutar B., \& Kulkarni, P. (2012). Cloud computing support for enhanced health applications. International Journal of Engineering and Innovative Technology, 2(1), 139-141.

[3] Lin, H. H., Hung, M. S., \& Wang, W. L. (2002). Software Project Management in Project Management. BestWish.

[4] Davis, F. D., Bagozzi, R. P., \& Warshaw, P. R. (1989). User acceptance of computer technology a comparison of two theoretical model. Management Science, 35(8), 982-1003.

[5] Hoffman, D. L., \& Novak, T. P. (1996). Marketing in hypermedia computer-mediated environments: Conceptual Foundations. Journal of Marketing, 60, 50-68. 
[6] Hoffman, D. L., \& Novak, T. P. (2009). Flow online: Lessons learned and future prospects. Journal of Interactive Marketing, 23, 23-34.

[7] Lee, Y. H., Hsieh, Y. C., \& Hsu, C. N. (2011). Adding Innovation diffusion theory to the technology acceptance model: supporting employee' intentions to use e-learning system. Educational Technology and Society, 14(4), 124-137.

[8] Hua, G., \& Haughton, D. (2009). Virtual words adoption: A research framework and empirical study. Online Information Review, 35(5), 889-900.

[9] Hsu, C. L., \& Lu, H. P., (2003). Why do people play on-line games? An extended tam with social influence and flow experience. Information and Management, 41, 853-868.

[10] Sanchez-Franco, M. J. (2006). Exploring the influence of gender on web usage via partial least squares. Behavior and Information Technology, 25(1), 19-36.

[11] Fetscherin, M., \& Lattermann, C. (2008). User acceptance of virtual worlds. Journal of Electronic Commerce Research, 9(3), 231-242.

[12] Zanna, M. P., \& Rempel, G. (1988). Attitudes: A new look at an old concept. The Social Psychology of Knowledge in Psychology of Knowledge. New York: Cambridge University Press.

[13] Ajzen, I., \& Fishbein, M. (1980). Understanding Attitudes and Predicting Social Behavior in Multiple Access Englewood Cliffs. NJ: Prentice Hall.

[14] Shin, D. (2009). The Evaluation of user experience of the virtual world in relation to extrinsic and intrinsic motivation. International Journal of Human-Computer Interaction, 25(6), 530-553.

[15] Csikszentmihalyi, M. (1997). Finding flow: The Psychology of Optimal Experience. New York: HarperCollins.

[16] Bakker, A. B. (2005). Flow among music teachers and their students: The crossover of peak experience. Journal of Vocational Behavior, 66, 26-44.

[17] Everton, W. J., Mastrangelo, P. M., \& Jolton, J, A. (2005). Personality correlates of employee's personal use of work computers. CyberPsychology and Behavior, 8, 143-153.

[18] Demerouti, E. (2006). Job characteristics flow and performance: The moderating role of conscientiousness. Journal of Occupational Health Psychology, 11(3), 266-280.

[19] Choi, D. H., Kim, J. K., \& Kim, S. H. (2007). ERP training with a web-based electronic learning system: The flow theory perspective. International Journal of Human-Computer Studies, 65, 223-243.

[20] Agarwal, R., \& Karahanna, E. (2000). Time flies when you are having fun: cognitive absorption and beliefs about information technology usage. MIS Quarterly, 24, 665-694.

[21] Bagozzi, R. P., \& Yi, Y. (1988). On the evaluation of structural equation model. Journal of Academy of Marketing Science, 16, 74-94.

[22] Anderson, J. C., \& Gerbing, D. W. (1998). Structural equation modeling in practice: A review and recommended two-step approach. Psychological Bulletin, 103, 411-423.

[23] Mantymaki, M., \& Salo, J. (2011). Teenagers in social virtual words: continuous use and purchasing behavior in Habbo Hotel. Computers in Human Behavior, 27, 2088-2097.

[24] Davis, F. D., (1989). Perceived usefulness perceived ease of use and user acceptance of information technology. MIS Quarterly, 13(3), 319-340.

[25] Moon, J., \& Kim, Y. (2001). Extending the TAM for a world-wide-web context. Information and Management, 38(4), 217-230.

[26] Karahanna, E., Straub, D. W., \& Chervany, N. L. (1999). Information technology adoption across time: A Cross-sectional comparison of pre-adoption and post-adoption beliefs. MIS Quarterly, 23(2), 183-213.

[27] Fredrickson, B. L. (2001). The role of positive emotions in positive psychology: The broaden-and-build theory of positive emotions. American Psychologist, 56, 218-226. 
[28] Bhattacherjee, A., \& Premkumar, G. (2004). Understanding changes in belief and attitude toward information technology usage a theoretical model and longitudinal test. MIS Quarterly, 28(2), 229-254.

[29] Bhattacherjee, A. (2001). Understanding information systems continuance an expectation-confirmation model. MIS Quarterly, 25(3), 351-370.

[30] Heieh, J. J. P., Rai, A., \& Kei, M. (2008). Understanding digital inequality: comparing continued use behavioral models of the socio-economically advantaged and disadvantaged. MIS Quarterly, 32(1), 97-26.

[31] Bakker, A. B. (2008). The work-related flow inventory: Construction and initial validation of the WOLF. Journal of Vocational Behavior, 72, 400-414.

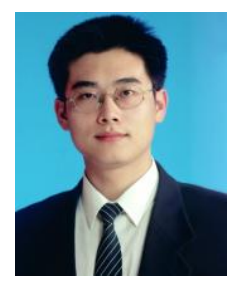

Chen-Lin Lee is a PhD student in the Department of Business Administration in Nanhua University in Taiwan. He is also a senior supervisor of Buddhist Dalin Tzu-Chi Hospital. His research interests lie in the fields of human resource management, medical material management and information management.

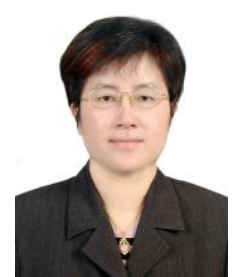

Li-Chuan Chu is a professor of the Department of Business Administration in Nanhua University in Taiwan. She received a PhD degree from the Department of Management Sciences at Tamkang University, Taiwan. Her research interests lie in the fields of human resource management, knowledge management and logistic management. She has published many papers regarding these fields.

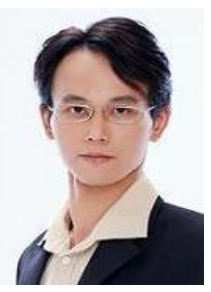

Kuo-Chung Huang is a professor and a chairman of Department of Business Administration in Nanhua University in Taiwan. He received a $\mathrm{PhD}$ degree from the Department of Management Sciences at Tamkang University, Taiwan. His research interests focus on the fields of modeling and computational intelligence, operations research. He has published many international journal papers regarding the above-mentioned fields. 